\title{
A Profile of Central Corneal Thickness (CCT) in Primary Open Angle Glaucoma in Trinidad and Tobago and the Implications \\ SA Lalchan
}

\section{INTRODUCTION}

It is well documented that both the prevalence and progression of glaucoma have greater tendencies in patients of Caribbean Descent $(1,2)$. Primary open angle glaucoma (POAG) occurs 10 years earlier, progresses faster and treatment modalities are less efficacious in our ethnicity (1). Thin corneas have been demonstrated as a strong independent predictor for the development of glaucomatous optic neuropathy following multivariate analysis $(3,4)$. The risk of developing POAG doubled for every $40 \mu \mathrm{m}$ decrease in central corneal thickness (CCT) from the overall mean of $573.3 \mu \mathrm{m}(5,6)$. The aim of the study was to profile the central corneal thickness within our patient population, assess the risk and outline the implications.

\section{METHODS}

A prospective, consecutive, observational study was conducted over one year period. All patients were examined by a Consultant Ophthalmologist as follows: history inclusive of specific risk factors for glaucoma, family history (aunt, uncle, grandparent, sibling, children) slit lamp examination, Goldmann applanation tonometry (GAT), indentation gonioscopy, ultrasound pachymetry (Microsoft Medical Devices the mean of 3 measurements taken at the centre of the pupil), dilated fundoscopy, stereo discs photography after maximum dilation (DRS camera and stereo-visual aids) and Humphreys 24-2 Standard automated perimetry used the Swedish interactive threshold algorithm on the Humphrey Visual Field Analyser 11 (Carl Zeiss Meditec).

Keywords: Central thickness, glaucoma, Trinidad and Tobago

From: LILY-The Eye Specialist Ltd, Chaguanas, Trinidad and Tobago.

Correspondence: S Lalchan, \#8 Endeavour Road, Chaguanas, Trinidad and Tobago

West Indies. Fax: 868-671-7211, email: mslalchan@ gmail.com 
Inclusion criteria were: age >18yrs, open angles, an intraocular pressure (IOP) of $\geq 21 \mathrm{mmHg}$; the presence of glaucomatous optic neuropathy (GON defined as thinning/ knotching of the neuroretinal rim, localised or diffuse, excavation; between eye asymmetry of 0.2; retinal nerve fibre layer defect): and/or visual field defect consistent with retinal nerve fibre layer damage; refractive error +3.0 to -5.0DS.

Perimetry's reliability indices were fixation loss $<33 \%$; false positive $<25 \%$ and false negative $<25 \%$. Standard automated perimetry visual field defects were considered abnormal if the PSD was triggered at the $5 \%, 2 \%, 1 \%$, or $0.5 \%$ levels.

All patients gave informed consent.

Exclusion criteria: primary angle closure glaucoma, secondary glaucoma, previous complex anterior segment/vitreoretinal procedures, diabetic retinopathy.

\section{RESULTS}

The sample size for patients with POAG was n 91 eyes (46 patients) and control was $n 92$ eyes [46 patients] (Table 1). The data for POAG and controls were: mean age 62 yrs (SD12yrs ) vs 54yrs (SD 13yrs); mean CCT 536um (SD 31.29um) vs 532um (SD 31.96um) p 0.21; family history of glaucoma $25 \%$ vs $23 \%$; essential hypertension $17 \%$ vs $9 \%$; diabetes mellitus $17 \%$ vs $41 \%$.

Notably, $80.2 \%$ of POAG and $78.3 \%$ of controls had CCT <555um (Fig 1). Further analysis of the Gaussian curve using 40um incremental decrease in CCT is demonstrated in colour columns. This clearly demonstrates that the majority of patients in both cohorts have 24 fold increased risk of developing POAG. Pertinently, it also shows the inherent danger of interpreting the IOP in isolation whereby thin corneas have an underestimation of the IOP. 


\section{DISCUSSION}

Primary open angle glaucoma (POAG) is the world's leading cause of bilateral irreversible blindness in developing countries $(7,8)$. Patients in the Caribbean are amongst the highest risk populations for developing glaucoma with a prevalence of up to $10 \%$ compared to $3 \%$ in patients of European Descent (1, 2, 9). Modern glaucoma specialists and diagnostic imaging increase the sensitivity and specificity of glaucoma detection; early diagnosis and treatment can prevent blindness $(10,11)$. These benefits need to filter down to developing countries.

Despite modern medicine, up to $90 \%$ of patients in developing countries are unaware $(12,13,14)$. The reasons are multi-factorial inclusive of patient factors, professional factors and policy-makers decisions. Patient factors include awareness/education, cultural attitudes, access to professional care and affordability to medications and specialist expertise. Professional factors include lack of awareness of the magnitude of the problem amongst the general physicians, misconceptions about diagnostics techniques and modern surgical techniques.

Additionally, policy-makers in developing countries tend to focus on cataracts and refractive errors as these have defined end points (9). There is far less emphasis on glaucoma care as the complexity includes chronicity, high expenditures (both medical and surgical) and skilled long-term professional support. Compounding this is the lack of appreciation of, the clearly defined roles of ophthalmologists in contrast to opticians. Only the former is trained to diagnose and treat any medical illness as defined by NICE (UK) and AAO guidelines and the laws of Trinidad and Tobago. Glaucoma is no exception.

There is no clear evidence to suggest that factors, inclusive of demographics, geography, genetics, cultural, social and/or economics, contribute significantly to poor outcomes in high risk patients (15). The seminal Ocular Hypertension Treatment Study (OHTS) was a 
randomised control trial which identified risk factors for conversion from ocular hypertension

to glaucomatous optic neuropathy (GON); statistically significant factors following

multivariate analysis were increasing age, large vertical/horizontal cup disc ratio, high intraocular pressure (IOP) and pattern standard deviation (specific measurement on Humphrey's perimetry 24-2 using SITA fast) and central corneal thickness (3-5).

Further analysis of the relationship with CCT showed an inverse relationship with the development of POAG (POAG $\infty 1 / \mathrm{CCT}$ ) ie the lower the CCT the greater the risk of developing POAG without a threshold effect (3) [Fig 1].

The clinical applications of CCT in glaucoma management are as follows: firstly, for simplicity, if the patients' CCT $<555 \mathrm{um}$, the risk increases 3.4 fold $^{4}$. Secondly, CCT is used in risk calculator measurements to help determine the risk of progression to glaucomatous optic neuropathy (3). Thirdly, corneal surgeries such as penetrating keratoplasty and LASIK (Laserassisted in-situ keratomileusis) modify the IOP parameters. It is important to note that CCT adjusted IOP is no longer applicable as there was no improvement in prediction models ${ }^{3}$.

In this study mean CCT was 536um for patients with POAG vs 532um for controls. This is comparable to other studies; of note the BESS (n 1142) had a CCT 529.8um vs Caucasians 545.2 um (16). Epidemiological studies have shown that patients of Caribbean Descent (CD), African Descent and Japanese have the lowest CCT [Table 1] $(17,18)$.

Notably, $80.2 \%$ of POAG and $78.3 \%$ of controls had CCT <555um (Fig 1). This is important. Firstly, it means approximately $80 \%$ of the entire study group, POAG and controls, has a 3.4 fold independent risk of developing POAG. Secondly, the predominance of thin corneas means inherently lower IOP measurements which are at risk of 'underestimation' (Table 2). This has several implications:

1) It is important to take a moment to outline the limitations of Goldmann IOP measurement which to date, remains the gold standard (19). It is based on Imbert-Fick's principle which states 
that the measurement of the internal pressure of a dry, thin walled sphere can be measured by an externally applied force (Fig 2). Note the cornea is neither thin, dry nor spherical; to reduce the errors the CCT is based on 530um, the tonometer head is $3.06 \mathrm{~mm}^{2}$ to compensate for the

surface tension of the tears and measures the very central aspect of the cornea (reducing the peripheral aspheric effect).

CCT and IOP both have an independent effect on the risk of developing GON, but these two factors also interact. When Goldmann applanation tonometry (GAT) was introduced in the 1950s, the thickness of the cornea was recognized as a potential confounder to IOP measurement.

2) CCT measurements are known to affect IOP measurements; if thin, there is an underestimation; if thick there is an overestimation. Of note, patients with diabetes mellitus are often observed to have thick CCT's; but this was the opposite in our study (20). Additionally, CCT is known to be a highly heritable trait (21). There are some who purport CCT is simply a phenotypic variation rather than a true risk factor. Our small gene pool may be reflective of this view.

3) Notably, many patients and non-medical eye care providers also believe that diagnosing glaucoma is simply 'a pressure check' ie the intraocular pressure. Glaucoma is defined as a heterogeneous group of diseases which results in damage to the nerve fibre layer. IOP is accepted as a risk factor not a defining factor; additionally, there are known IOP and non-IOP dependent factors.

The reason for IOP remaining important is that, to date it is the only modifiable risk factor. It is also well documented globally, that $90 \%$ of patients with POAG have IOP $<21 \mathrm{mmHg}$ (previously classified as normal tension glaucoma). It is now clear to 
IOP alone is misleading for both diagnosing and monitoring glaucoma.

Therein lays the danger when patients and non-medical eye care providers assume IOP is 'normal'. The situation becomes dire when the IOP is underestimated in the presence of thin

CCT applicable for $78 \%$ of the control sample (Table 2). In fact, BESS in 2007 showed a fourfold greater risk of developing POAG if patients are only monitored by opticians (22). It also demonstrated that patients have a greater chance of delayed diagnosis if only seen by a non-medic eye care provider, hence the importance of the ophthalmologist in early diagnosis (23). Other studies reflect this, so much so that, the recommendations are that patients need to be screened by an ophthalmologist. This is also comparable to NICE and AAO guidelines.

4) It is important to note there is no specific single examination or test that confirms glaucoma diagnosis, especially in the very early stages. An IOP measurement alone cannot indicate the absence or presence of the disease. This is an important barrier towards accessing a comprehensive glaucoma diagnostic assessment. Modern diagnosis of early glaucoma includes: tonometry, pachymetry, gonioscopy stereoscopic optic nerve viewing/photography, perimetry and laser-assisted optic nerve imaging $(1,3)$. Often, it is such that the various components have to be considered as pieces of a puzzle, notably with clinical impression at the core of evaluation of modern diagnostics ie 'glaucoma composites' [Fig 3] (24).

It is no different form a formal cardiac, renal or neurological assessments requiring the necessary investigations and expertise.

The second major risk factor identified in this study was family history. The family history rates are high within our population with $25 \%$ in POAG group and $23 \%$ in control reporting a first/second degree family history. Other studies in high risk patients report similar rates. The presence of family history independently increases the risk of POAG 10 fold. There are currently three well documented genes ie myocilin, optineurin and WGR. Myocilin the most well know, contribute to only $3 \%$ of POAG. 
There is no convincing evidence that DM is a factor for development of POAG. It is well know that DM has thick corneas and some studies have felt DM to be protective of POAG risk. It was quite surprising to the authors to find the opposite in our population. DM patients constituted $41 \%$ of controls of which the group demonstrated a comparable mean CCT with $78 \%$ have $\mathrm{CCT}<555 \mathrm{um}$.

Local internal auditing (n 3360) showed a prevalence of $10 \%$ n 340, with $26.5 \%$ under 50yrs (comparable to international statistics), with $20 \%$ presenting with moderate to severe visual field loss. The prevalence is not surprising given the risk factors outlined: $80 \%$ thin CCT, $25 \%$ family history. However, the severity at presentation is disappointing. More needs to be done; more can be done:

1 Public awareness campaigns will improve education and awareness;

2 Affordability of medications on CDAP will mean better access to modern treatment;

3 Targeted training for ophthalmic surgeons in the public sector

4 Adoption of internal auditing to ensure safe outcomes for patients

5 A national glaucoma screening programme- Consultant-led (this is challenging as to date there is no established programme globally. There are some pilots with very good results.

6 The realisation by all, policy-makers, the university, medical professionals and patients, that early diagnosis requires an ophthalmologist not an optician.

This study adds to the body of evidence that we have the highest risk; equally important to note is, more needs to be done. On the shop floor patients, non-medical professional and general practitioners need to be more aware of the precise components necessary to diagnosis glaucoma early to reduce blindness rates. Policy makers need to take a more active role in public education and improving the affordability of glaucoma medications.

These patients continue to go blind silently. The time to effect change has always been now. 


\section{CONCLUSION}

This study demonstrates that $80 \%$ POAG and $78 \%$ controls have a CCT $<555 \mathrm{um}$. Interestingly, both controls and POAG has similar CCT. Additionally, approximately $25 \%$ in both groups had a family history of glaucoma. This study demonstrates predominately thin corneas, with a three-fold risk of glaucoma. This may further increase the risk and the author recommends

vigilance in these patients. Additional long term study of the cohort will further qualify progression and rates of conversion to glaucoma. The need for improved efforts towards developing screening programmes, earlier detection and timely intervention is clearly evident.

\section{ACKNOWLEDGEMENT}

Presented in part:ESCRS London 2015 (European Cataract \& Refractive Surgery) $6^{\text {th }}$ Global Ophthalmologists Annual Meeting Japan 2016. 


\section{REFERENCES}

1. Racette L, Wilson MR, Zangwill LM, Weinreb RN, Sample PA. Primary open-angle glaucoma in blacks: a review. Surv Ophthalmol 2003; 48: 295-313.

2. Leske MC, Wu SY, Hennis A, et al. BESs Study Group. Risk factors for incident openangle glaucoma: the Barbados Eye Studies. Ophthalmology. 2008; 115: 85-93.

3. Brandt JD, Gordon MO, Gao F, Beiser JA, Miller P, Kass M for the Ocular Hypertension Treatment Study Group. Adjusting Intraocular Pressure for Central Corneal Thickness Does Not Improve Prediction Models for Primary Open-Angle Glaucoma. Ophthalmology 2012; 119: 437-42.

4. Ocular Hypertension Treatment Study Group, European Glaucoma Prevention Study Group.Validated prediction model for the development of primary open-angle glaucoma in individuals with ocular hypertension. Ophthalmology. 2007; 114:10-9.

5. Gordon MO, Beiser JA, Brandt JD, et al. Ocular Hypertension Treatment Study Group. The OcularHypertension Treatment Study: baseline factors that predict the onset of primary open-angle glaucoma. Arch Ophthalmol. 2002; 120: 714-20.

6. Medeiros FA, Sample PA, Zangwill LM et al. Corneal thickness as a risk factor for visual field loss in patients with preperimetric glaucomatous optic neuropathy. Am J Ophthalmol. 2003; 136:805-13.

7. Varma R, Vajaranant TS, Burkemper B, Wu S, Torres M, Hsu C, Choudhury F, McKean-Cowdin R. Visual Impairment and Blindness in Adults in the United States: Demographic and Geographic Variations From 2015 to 2050. JAMA Ophthalmol. 2016 May 19.

8. Quigley HA, Broman AT. The number of people with glaucoma worldwide in 2010 and 2020. Br J Ophthalmol. 2006; 90: 262-7. 
9. Leske MC, Heijl A, Hyman L et al. EMGT Group. Predictors of long-term progression in the Early Manifest Glaucoma Trial. Ophthalmology 2007; 114: 1965-72.

10. Reus NJ, Lemij HG, Garway-Heath DF, Airaksinen PJ, Anton A, Bron AM, Faschinger C, Holló G, Iester M, Jonas JB, Mistlberger A, Topouzis F, Zeyen TG. Clinical assessment of stereoscopic optic disc photographs for glaucoma: the European Optic Disc Assessment Trial. Ophthalmology. 2010; 117: 717-23.

11. van der Schoot J, Reus NJ, Garway-Heath DF, Saarela V, Anton A, Bron AM et al. Accuracy of matching optic discs with visual fields: the European Structure and Function Assessment Trial (ESAFAT). Ophthalmology 2013; 120: 2470-5.

12. Leite MT, Sakata LM, Medeiros FA. Managing glaucoma in developing countries. Arq Bras Oftalmol 2011; 74: 83-4.

13. Rotchford AP, Kirwan JF, MullerMA, Johnson GJ, Roux P. Temba glaucoma study: a population-based cross-sectional survey in urban South Africa. Ophthalmology. 2003; 1 10: $376-82$.

14. Hennis A, Wu SY, Nemesure B, Honkanen R, Leske MC; Barbados Eye Studies Group. Awareness of incident open-angle glaucoma in a population study: the Barbados Eye Studies. Ophthalmology. 2007; 114: 1816-21.

15. Sample PA, Girkin CA, Zangwill LM, Jain S, Racette L, Becerra LM et al. African Descent and Glaucoma Evaluation Study Group. The African Descent and Glaucoma Evaluation Study (ADAGES): design and baseline data. Arch Ophthalmol 2009; 127: $1136-45$.

16. Nemesure B, Wu SY, Hennis A, Leske MC. Barbados Eye Study Group. Corneal thickness and intraocular pressure in the Barbados eye studies. Arch Ophthalmol 2003; 121: $240-4$. 
17. Nangia V, Jonas JB, Sinha A, Matin A, Kulkarni M. Central corneal thickness and its association with ocular and general parameters in Indians: the Central India Eye and Medical Study. Ophthalmology 2010; 117: 705-10.

18. Aghaian E, Choe JE, Lin S, Stamper RL. Central corneal thickness of Caucasians, Chinese, Hispanics, Filipinos, African Americans, and Japanese in a glaucoma clinic. Ophthalmology. 2004; 111: 2211-9.

19. Goldmann H, Schmidt T. Applanation tonometry [in German]. Opthalmologica. 1957; 134: $221-42$.

20. Ehlers N, Bramsen T, Sperling S. Applanation tonometry and central corneal thickness. Acta Ophthalmol (Copenh) 1975; 53: 34-43.

21. Dimasi DP, Burdon KP, Craig JE. The genetics of central corneal thickness. Br J Ophthalmol. 2010; 94: 971-6.

22. Hennis A, Wu SY, Nemesure B, Honkanen R, Leske MC. Awareness of incident openangle glaucoma in a population study: the Barbados Eye Studies. Ophthalmology. 2007; 114: $1816-21$.

23. Hollands H, Johnson D, Hollands S, Simel DL, Jinapriya D, Sharma S. Do findings on routine examination identify patients at high risk for primary open-angle glaucoma? J Ame Med Assoc 201; 309, No 19.

24. Lalchan SA, Singh V. Glaucoma diagnostics for the clinician 'OPEN YOUR EYES" your pivotal role in improving glaucoma care in our high risk population. West Indian Med J 2016 June 30. doi:10.7727/wimj.2016.090 
Table 1: Demographics of study sample in Trinidad and Tobago (T\&T) and other ethnic groups.

\begin{tabular}{|c|c|c|c|c|c|c|}
\hline & $\begin{array}{l}\text { POAG } \\
\text { T\&T }\end{array}$ & Control & $\underset{6}{\text { BESS }^{1}}$ & ${\underset{7}{7}}^{\text {Nangia }}{ }^{1}$ & $\begin{array}{l}\text { Caucasians } \\
18\end{array}$ & $\begin{array}{l}\text { Japanese } \\
18\end{array}$ \\
\hline $\begin{array}{l}\text { Sample size } \\
\text { (no. of eyes) }\end{array}$ & 91 & 92 & & & & \\
\hline $\begin{array}{l}\text { Mean age } \\
(\mathrm{yrs})\end{array}$ & $\begin{array}{l}62 \\
(\mathrm{SD} 12)\end{array}$ & $54(13)$ & & & & \\
\hline $\begin{array}{l}\text { Mean CCT } \\
\mu \mathrm{m}\end{array}$ & $\begin{array}{l}535.6 \\
\text { (SD31.2 } \\
9)\end{array}$ & $\begin{array}{l}531.5(31.96) \mathrm{p} 0.2 \\
1\end{array}$ & 529.8 & 514 & 550.4 & 531.7 \\
\hline $\begin{array}{l}\text { Family } \\
\text { History } \\
\text { POAG }\end{array}$ & $25 \%$ & $23 \%$ & & & & \\
\hline $\begin{array}{l}\text { Diabetes } \\
\text { mellitus }\end{array}$ & $17 \%$ & $41 \%$ & & & & \\
\hline $\begin{array}{l}\text { Essential } \\
\text { hypertension }\end{array}$ & $17 \%$ & $9 \%$ & & & & \\
\hline
\end{tabular}

Table 2: Demonstrates the effect of CCT on IOP measurement. Thin corneas underestimate the IOP. Though CCT-corrected IOP does not improve prediction, the data demonstrates that at a measured IOP of $21 \mathrm{mmHg}$, a patient with CCT of $475 \mathrm{um}$ will actually be $26 \mathrm{mmHg}$ etc. Hence the importance in recognising the dangers of the 'normal' IOP.

\begin{tabular}{|c|c|c|c|c|c|}
\hline \multicolumn{2}{|c|}{ Modified Ehler's correction factor algorithm } & \multirow{2}{*}{$\begin{array}{l}21 \mathrm{mmhg} \\
\text { GAT } \\
\text { w/Correct }\end{array}$} & \multirow[b]{2}{*}{ POAG no } & \multirow[b]{2}{*}{ Control n } & \multirow[b]{2}{*}{ Clinical comments } \\
\hline $\mathrm{CCT} \mu \mathrm{m}$ & $\begin{array}{l}\text { Correction } \\
\mathrm{mmHg}\end{array}$ & & & & \\
\hline 410 & 10 & 31 & & & \\
\hline 415 & 10 & 31 & & & \\
\hline 420 & 9 & 30 & & & \\
\hline 425 & 9 & 30 & & & \\
\hline 430 & 8 & 29 & & & \\
\hline 435 & 8 & 29 & & & \\
\hline 440 & 7 & 28 & & & \\
\hline 445 & 7 & 28 & 1 & & \\
\hline
\end{tabular}


Lalchan

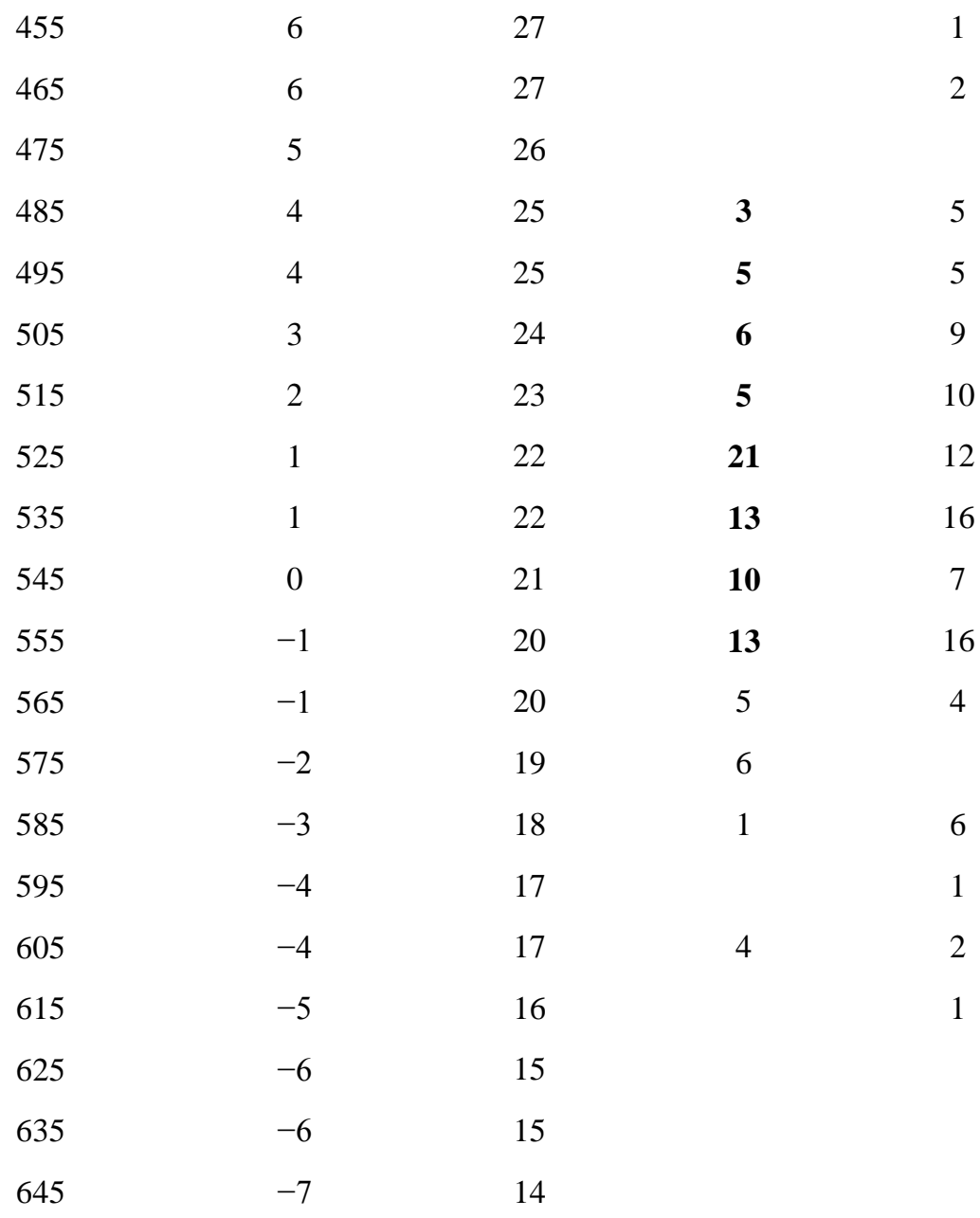

(CCT-central corneal thickness, IOP- intraocular pressure) $78 \%$ of patients are $<555 \mu \mathrm{m}$ meaning that their IOP's are understated. 


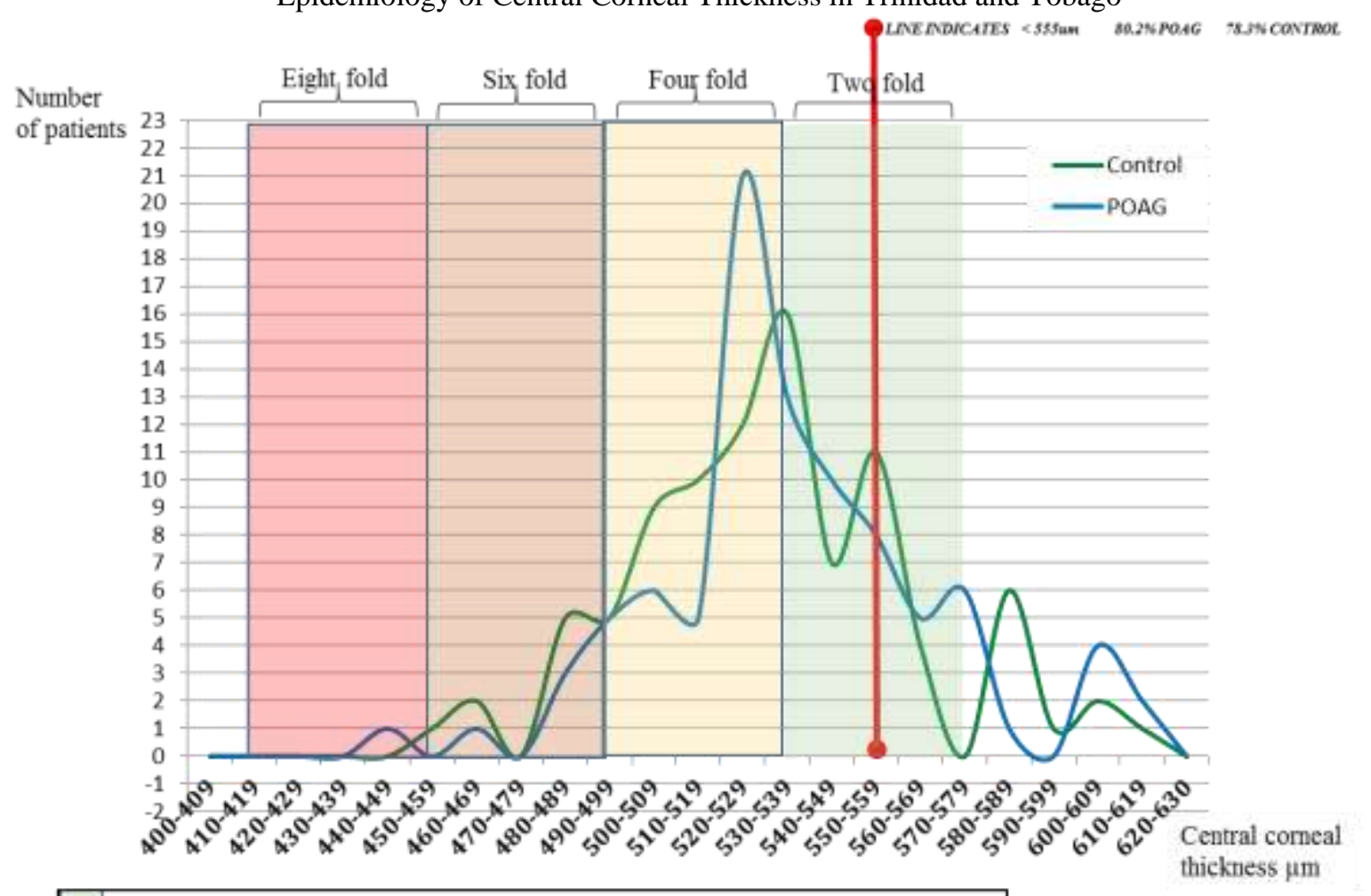

574-534 $\mu \mathrm{m}$, the risk of glaucoma increases two fold.

$533-493 \mu \mathrm{m}$, the risk of glaucoma increases four fold.

$492-452 \mu \mathrm{m}$, the risk of glaucoma increases six fold.

$451-411 \mu \mathrm{m}$, the risk of glaucoma increases eight fold.

Fig 1: Gaussian curve plot of the range of CCT for both POAG and controls groups. Two salient features include, firstly, the majority of patients had a CCT of $<555 \mathrm{um}$. Secondly, using 40um incremental decrease in CCT indicates the majority of patients have a 2-4 fold independent risk factor.

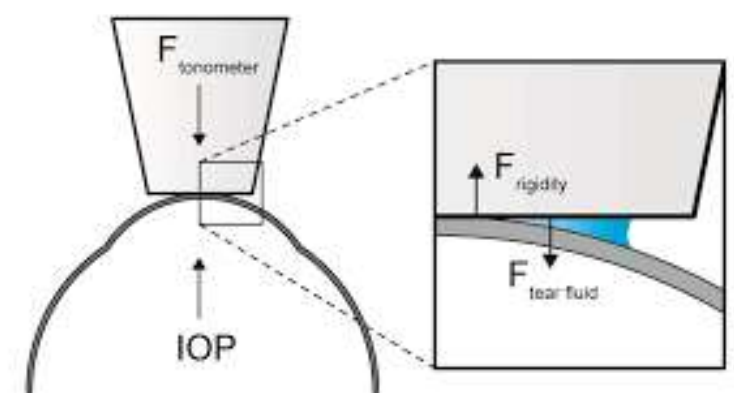

Fig 2: Imbert-Fick's principle which is used to calculate IOP. The cornea is neither a dry nor thin-walled sphere; multiple correction factors are used to calculate the IOP. The central corneal thickness is one factor that requires compensation. 


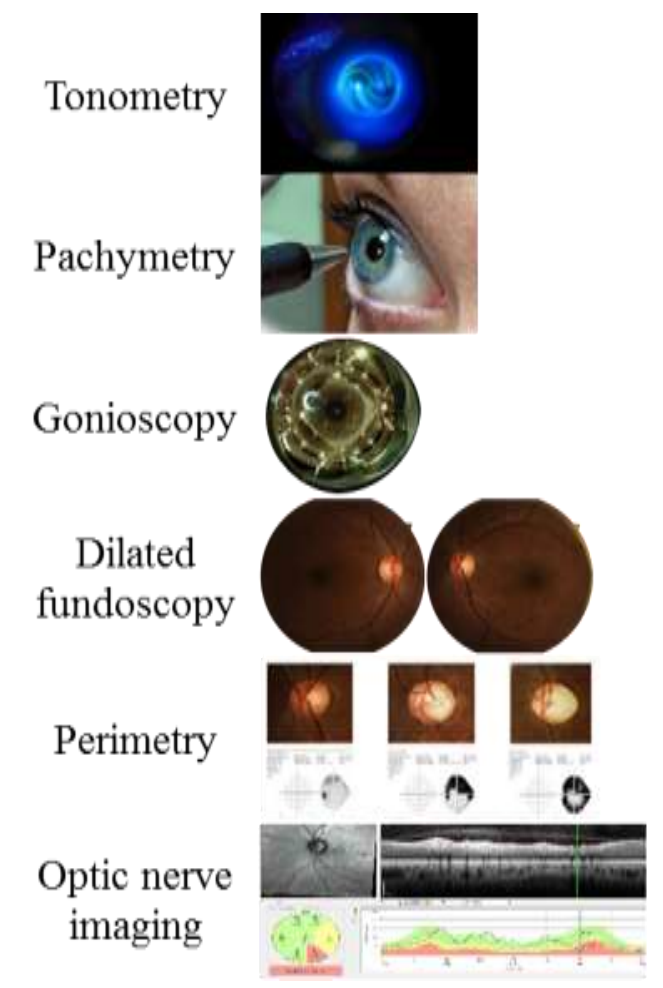

Fig. 3: 'Glaucoma Composites' inclusive of the clinical features necessary to diagnose glaucoma. 